\title{
Influence of the power supply parameters on the projectile energy in the permanent magnet electrodynamic accelerator
}

\author{
Andrzej Waindok ${ }^{1}$, and Paweł Piekielny ${ }^{1, *}$ \\ ${ }^{1}$ Opole University of Technology, Department of Electrical Engineering and Mechatronics, 45-920 Opole, ul. Prószkowska 76, \\ Poland
}

\begin{abstract}
The main objective of the research is to investigate, how the power supply parameters influence the kinetic energy of the movable element, called commonly a projectile or bullet. A calculation and measurement results of transient characteristics for an electrodynamic accelerator with permanent magnet support were presented in the paper. The calculations were made with using field-circuit model, which includes the parameters of the power supply, mass of the bullet and friction phenomenon. Characteristics of energy and muzzle velocity verso supply voltage ( $50 \mathrm{~V}$ to $350 \mathrm{~V})$ and capacitance value $(60 \mathrm{mF}$ to $340.5 \mathrm{mF})$ were determined, as well. A measurement verification of selected points of calculation characteristics were carried out for investigated values of muzzle velocity. A good conformity between calculation and measurement results was obtained. Concluding, presented characteristics of the muzzle velocity and energy of the projectile vs. power supply parameters indicate, that accelerators could be used for fatigue testing of materials.
\end{abstract}

\section{Introduction}

Electrodynamic accelerators (EA), commonly called railguns, are investigated for many years $[1,2]$. Mostly these researches were dedicated to military applications [3-5]. However, in recent years, the application of the accelerators in the material testing becomes more popular [6]. Studies on dynamic defragmentation of planetary materials [7] and hypervelocity material testing [8] by using an accelerator are carried out, especially. The use of accelerators for fatigue testing of materials has many advantages: wide measuring range, high velocity impact tests and the possibility of using a ballistic part with different face geometry. These advantages allow to use accelerators in the material testing in industry, in military and especially in the area related with exploration of the space [9].

The fatigue testing of materials can also include study of rails and projectile materials which work under extreme conditions. The shape of rails and projectile is also very important and influences the system efficiency significantly [10-13].

For fatigue testing of materials, an important aspect is the precise determination of the impact energy over a large range of its changes. The value of the projectile energy depends on its mass and velocity. Through an appropriate choice of the power supply parameters (voltage and capacity) it is possible to control the muzzle velocity. Thus, the prediction of the projectile energy, based on the parameters of the power supply system, mass and geometry of the projectile face, is very important. This can be achieved by appropriately formulated computational model of the accelerator.
In order to increase the efficiency of the railgun there is a need to conduct the experimental work and create a proper calculation model of the system. The appropriate choice of calculation method and variables influencing the work of the whole system is very important for analysis of the device operation [14-17]. The model could be used, for example, in order to increase the thrust, without increasing the excitation current [18]. The main aim of this study is the prediction of the projectile energy with using the presented calculation model.

\section{Physical model}

The analysis was done for the hybrid accelerator with ferromagnetic core and permanent magnets (Fig. 1). For this solution, the magnetic field has two sources: a current flowing through the circuit and permanent magnets. This type of accelerators allows to increase the value of the magnetic field in the projectile area for the same power supply configuration.

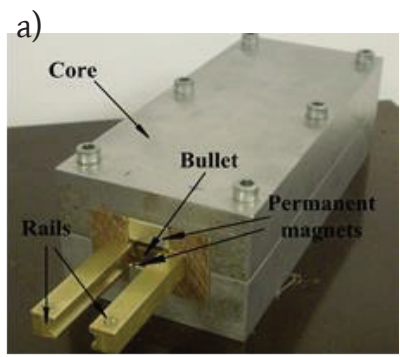

b)

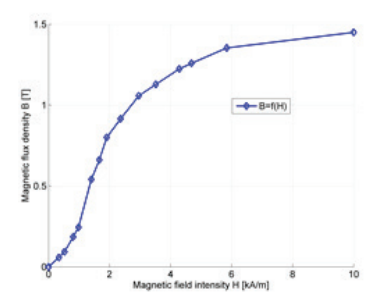

Fig. 1. a) Picture of the accelerator, b) B/H curve of the core steel.

\footnotetext{
* Corresponding author: p.piekielny@po.opole.pl
} 
For the construction with permanent magnets, it is important to take care about the circuit connections in the power system. There is a possibility of demagnetization of permanent magnets in case of power supply reverse polarity. The blocking diode between the thyristor and the ground of the capacitors bank has been used to prevent capacitor charging in the negative direction.

The 3D visualization of the laboratory stand used in the measurement verification is presented in Fig. 2. As an energy source a capacitors bank with a total capacity of $340.5 \mathrm{mF}$ and nominal voltage of $250 \mathrm{~V}$ was used.

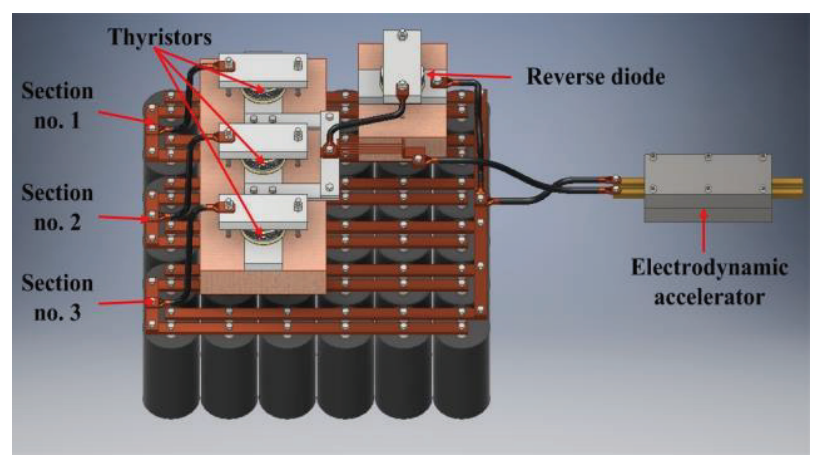

Fig. 2. 3D visualization of the investigated system.

In order to control the power source energy more precisely, the capacitor battery is divided into three sections of the same capacity. Each section is triggered with a separate thyristor (model T95-1900 from Kubara LAMINA Company). Current measurement was made in common ground of thyristors by recording the voltage drop on a $0.517 \mathrm{~m} \Omega$ resistance. Velocity of the projectile was determined by measuring the flight time through the optical gate at the end of rails.

During the shot the following signals were recorded with using an oscilloscope: the voltage on the capacitor bank $u$ and the excitation current $i$.

\section{Calculation model}

The calculations have been made with using a field-circuit method. The field parameters, which are magnetic flux density and thrust, have been determined with using finite element method (FEM) in Maxwell software. The voltage boundary conditions were assumed on the rails ends and on the outer boundaries the zero Dirichlet condition was assumed. The nonlinear B-H curve has been included in the model (Fig. 1b). Maxwell's equations in the following form have been solved:

$$
\nabla \times \mathbf{H}=\mathbf{J} ; \nabla \times \mathbf{E}=0 ; \nabla \bullet \mathbf{B}=0
$$

where:

$$
\begin{array}{ll}
\mathbf{H} & \text { - magnetic intensity vector }[\mathrm{A} / \mathrm{m}], \\
\mathbf{J} & \text { - current density vector }\left[\mathrm{A} / \mathrm{m}^{2}\right], \\
\mathbf{E} & \text { - electric intensity vector }[\mathrm{V} / \mathrm{m}], \\
\mathbf{B} & - \text { magnetic flux density vector }[\mathrm{T}]
\end{array}
$$

An exemplary magnetic flux and current distribution is presented in Fig. $3(U=100 \mathrm{~V}, z=0.1 \mathrm{~m})$. The highest value of the magnetic flux is observed in the projectile area (about $5.14 \mathrm{~T}$ ). The largest value of the current density (Fig. 3b) is observed in the area of the bullet, on the inner edges of the connecting elements (over $3.9 \mathrm{kA} / \mathrm{mm}^{2}$ ).

a)

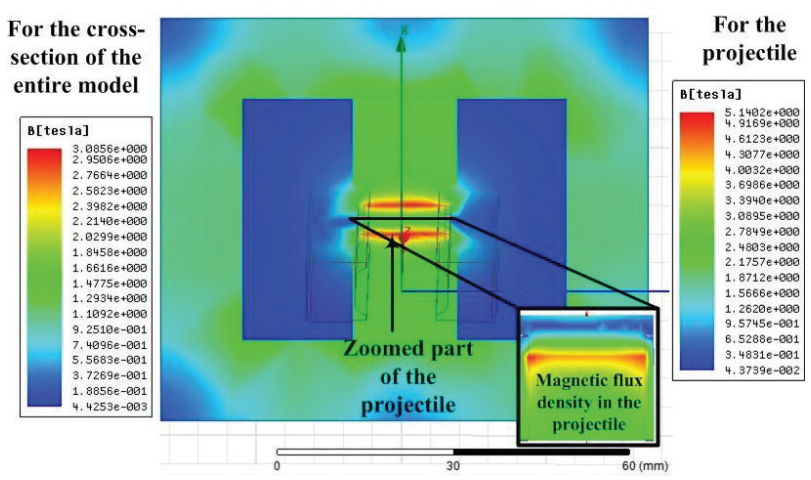

b)

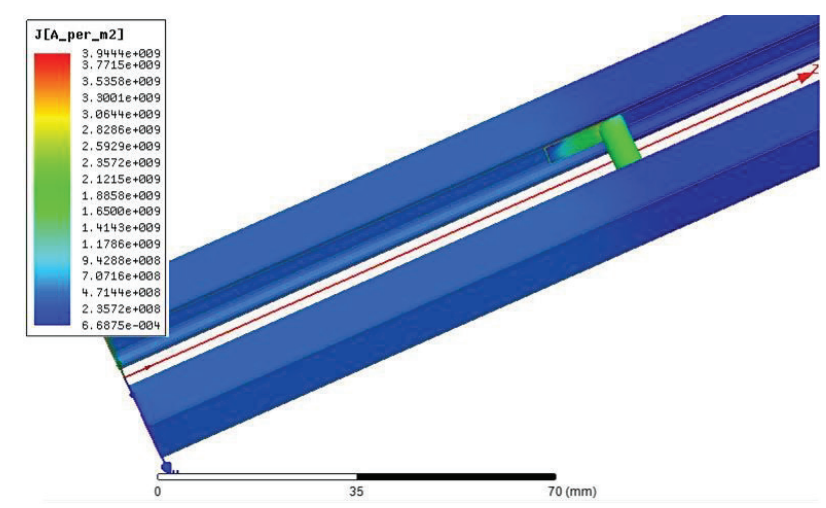

Fig. 3. a) Magnetic flux distribution in the cross section of the railgun, b) Excitation current density distribution in the rails and projectile $(U=100 \mathrm{~V}, z=0.1 \mathrm{~m})$.

Using the model, the current and magnetic flux distributions were determined, which are needed to calculate the magnetic flux and Lorentz force. The magnetic flux $\Phi$ is calculated with using the integral:

$$
\Phi=\int_{S} \mathbf{B} \bullet \mathbf{n} d S
$$

where:

n - unit vector normal to surface $S$,

$\mathrm{S}$ - surface limited by the rails and projectile, parallel to the plane YZ (Fig. 3).

The source of the thrust is a Lorentz force $\mathbf{F}$ :

$$
\mathbf{F}=\int_{\Omega_{m}}(\mathbf{J} \times \mathbf{B}) d \Omega_{m}
$$

where:

$\Omega_{m} \quad$ - volume of the projectile $\left[\mathrm{m}^{3}\right]$.

In Fig. $4(U=100 \mathrm{~V}, z=0.1 \mathrm{~m})$ the volume force density in rails and projectile is presented. The highest value of force density, directed along z-axis, is observed in the area of the projectile. In the case of rails the value of acting force density is lower than in the projectile and is directed along $y$-axis out of the rails. 


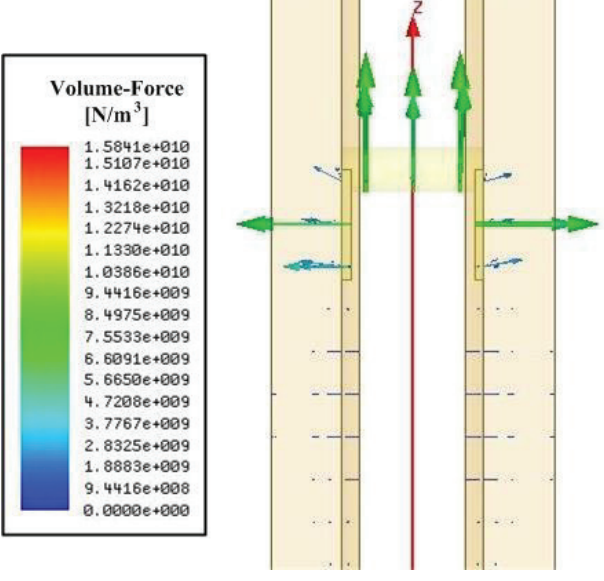

Fig. 4. Volume force density in rails and projectile.

In the transient calculations, the dynamic inductance $L_{d}$ is an important parameter

$$
L_{d}=\frac{\partial \Phi}{\partial i}=\frac{1}{i} \frac{\partial W_{m}}{\partial i}
$$

where:

$$
\begin{array}{ll}
i & - \text { current flowing through the rails }[\mathrm{A}], \\
W_{m} & - \text { magnetic energy }[\mathrm{J}] .
\end{array}
$$

The circuit model is described by the ordinary differential equations in the form:

$$
\begin{gathered}
\frac{d v}{d t}=\frac{F(i, x)-D v}{m} ; \frac{d x}{d t}=v \\
\frac{d i}{d t}=\frac{-R i-\frac{d}{d x}(\Phi(i, x)) v-\frac{q}{C}}{\frac{d}{d i} \Phi(i, x)}
\end{gathered}
$$

where:

$$
\begin{array}{ll}
R & \text { - resistance of the accelerator circuit }[\Omega], \\
v & \text { - projectile velocity }[\mathrm{m} / \mathrm{s}], \\
q & \text { - capacitor charge }[\mathrm{C}], \\
C & \text { - capacitance of the capacitor banks }[\mathrm{F}] .
\end{array}
$$

The circuit parameters (Table 1) have been obtained based on measurements and analytical calculations.

Table 1. Main circuit parameters of the model.

\begin{tabular}{|c|c|c|}
\hline Quantity & Unit & Value \\
\hline Projectile mass $m$ & {$[\mathrm{~g}]$} & 4.6 \\
\hline Friction coefficient $D$ & {$[\mathrm{Ns} / \mathrm{m}]$} & 0.4 \\
\hline Drag coefficient $C_{x}$ & - & 1.05 \\
\hline $\begin{array}{c}\text { Accelerator circuit } \\
\text { resistance } R\end{array}$ & {$[\mathrm{~m} \Omega]$} & $1.82-2.2$ \\
\hline $\begin{array}{c}\text { Accelerator circuit } \\
\text { inductance } L\end{array}$ & {$[\mu \mathrm{H}]$} & $0.84-0.89$ \\
\hline
\end{tabular}

The field-circuit model was implemented in Matlab/Simulink software (the block diagram is presented in Fig. 5). In order to use the model, the thrust and magnetic flux values vs. excitation current and projectile position have been determined (Figs. 6 and 7) and included in the model with using Look-up tables.

In the mechanical part of the model, in order to increase the calculation precision, the drag coefficient is taken into account. The air resistance $P$ is calculated based on equation:

$$
P=0.5 C_{x} g A v^{2}
$$

where:

$$
\begin{array}{ll}
\mathrm{g} & - \text { air density }\left(1.2 \mathrm{~kg} / \mathrm{m}^{3}\right), \\
A & \text { - area of the projectile front part }\left(120 \mathrm{~mm}^{2}\right),
\end{array}
$$$$
v \quad-\text { muzzle velocity. }
$$

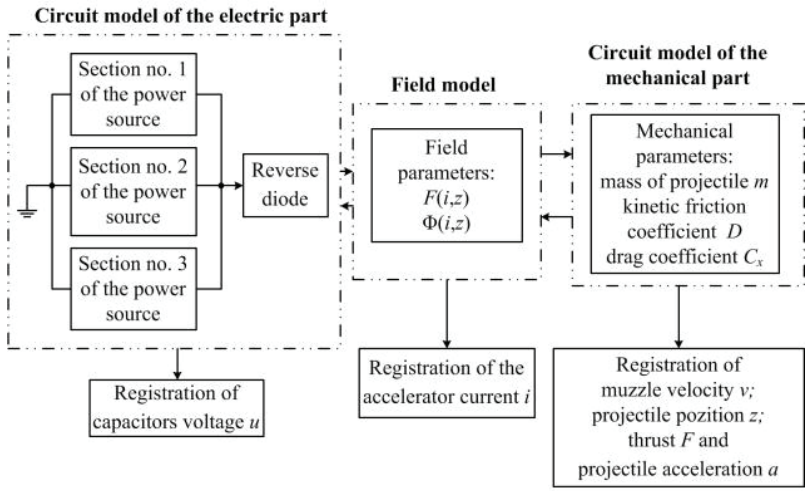

Fig. 5. The field-circuit model

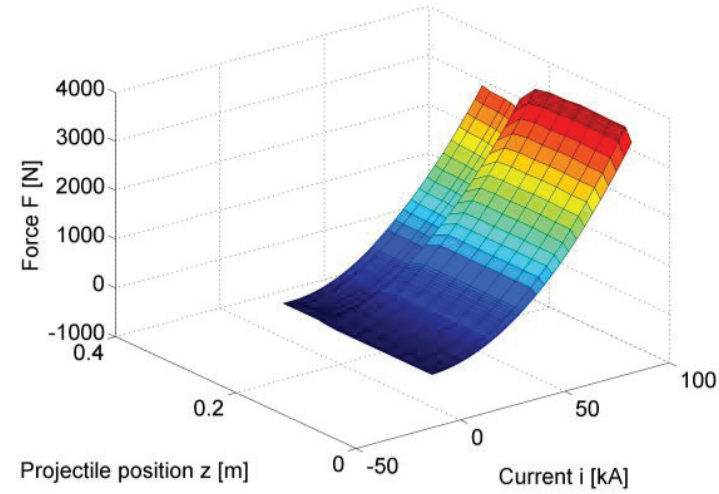

Fig. 6. Thrust vs. current and projectile position values.

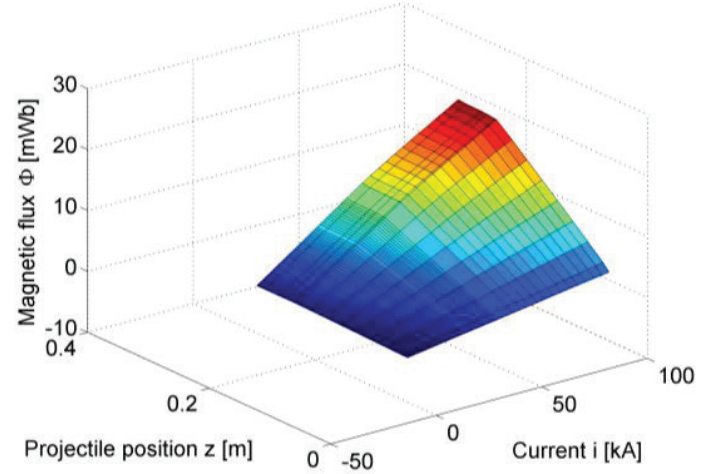

Fig. 7. Magnetic flux vs. current and projectile position values. 


\section{Measurement verification}

The mathematical model was verified for different values of capacitances and voltages. In Figs. 8-11 some transients are presented. a) 15

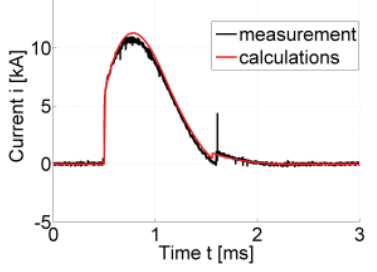

b)

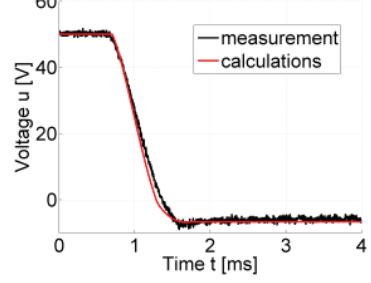

Fig. 8. Excitation current (a) and capacitor voltage (b) transients for $U=50 \mathrm{~V}$ and $C=114 \mathrm{mF}$.
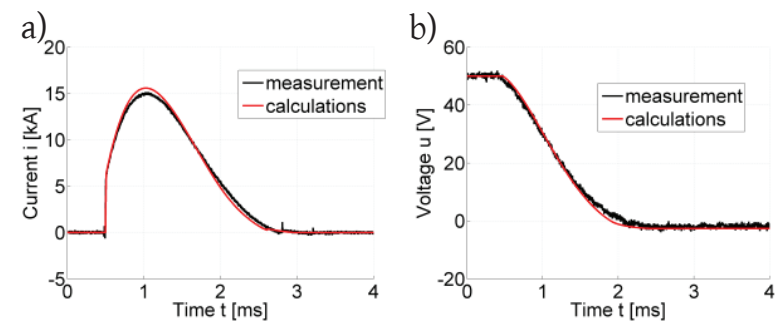

Fig. 9. Excitation current (a) and capacitor voltage (b) transients for $U=50 \mathrm{~V}$ and $C=340.5 \mathrm{mF}$.

The increasing of capacitance by a factor 3 , causes only a slightly increasing in the peak current value (from $12 \mathrm{kA}$ to $15 \mathrm{kA}$ ). The duration of the impulse increases by almost $70 \%$. The increasing of voltage by factor 2 causes proportional increasing of peak current value. The duration time does not change vs. voltage value. The shapes of the measured waves are very similar to the calculated ones.
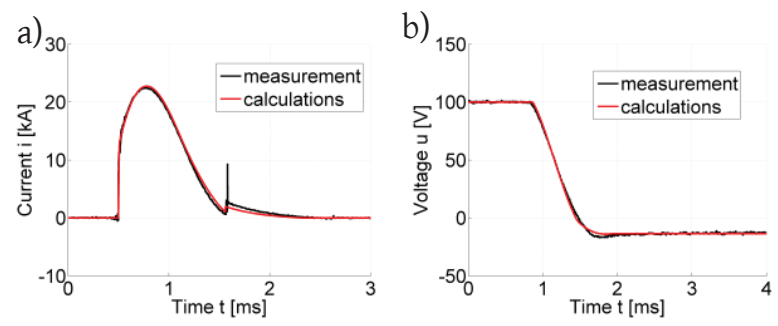

Fig. 10. Excitation current (a) and capacitor voltage (b) transients for $U=100 \mathrm{~V}$ and $C=114 \mathrm{mF}$.
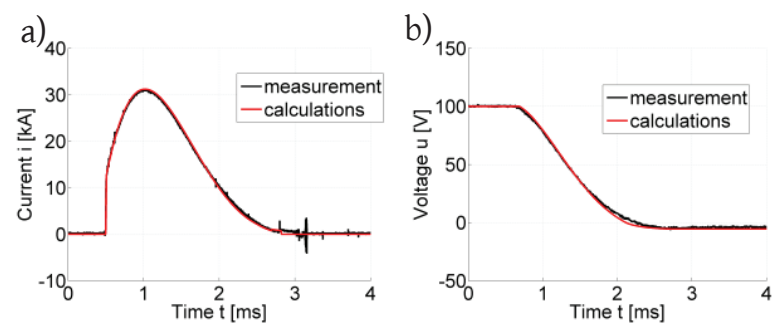

Fig. 11. Excitation current (a) and capacitor voltage (b) transients for $U=100 \mathrm{~V}$ and $C=340.5 \mathrm{mF}$.

The exit muzzle velocity and peak current value were verified as well. Some measurement verification values have been given in Table 2. There is a very good conformity visible in the measured and calculated peak current values. It means, that the electrical part of the model is quite correct. Some problems are observed in the measurement verification of muzzle velocity. For low energies there is a huge difference between them. For higher energies the differences between measurements and calculations of muzzle velocity are lower. It means, that there are some problems with the mechanical part of the model. The main problem is the proper consideration of the friction and drag force. The experiments show, that these forces changes vs. source energy. It could be due to force acting on the rails, which changes slightly the distance between rails, and consequently the friction coefficient. Additionally, the drag coefficient could be different for higher velocities (more than $100 \mathrm{~m} / \mathrm{s}$ ).

Table 2. Measurement verification of the exit muzzle velocity and peak current value

\begin{tabular}{|c|c|c|c|c|}
\hline $\begin{array}{c}\text { Initial capacitor } \\
\text { voltage and } \\
\text { capacitance } \\
\text { value }\end{array}$ & \multicolumn{2}{|c|}{$\begin{array}{c}\text { Velocity } \\
{[\mathrm{m} / \mathrm{s}]}\end{array}$} & \multicolumn{2}{c|}{$\begin{array}{c}\text { Peak current } \\
\text { [kA] }\end{array}$} \\
\cline { 2 - 5 } & $\begin{array}{c}\text { Measu } \\
\text {-red }\end{array}$ & $\begin{array}{c}\text { Calcul- } \\
\text { ated }\end{array}$ & $\begin{array}{c}\text { Measu } \\
\text {-red }\end{array}$ & $\begin{array}{c}\text { Calcul- } \\
\text { ated }\end{array}$ \\
\hline $\begin{array}{c}U=50 \mathrm{~V}, \\
C=114 \mathrm{mF}\end{array}$ & 13.37 & 4.41 & 11.03 & 11.29 \\
\hline $\begin{array}{c}U=50 \mathrm{~V}, \\
C=340.5 \mathrm{mF}\end{array}$ & 48.64 & 41.45 & 15.15 & 15.58 \\
\hline $\begin{array}{c}U=100 \mathrm{~V}, \\
C=114 \mathrm{mF}\end{array}$ & 44.80 & 40.73 & 22.63 & 22.75 \\
\hline $\begin{array}{c}U=100 \mathrm{~V}, \\
C=340.5 \mathrm{mF}\end{array}$ & 126.26 & 140.53 & 31.33 & 31.19 \\
\hline
\end{tabular}

\section{Analysis of the projectile energy vs. supply parameters}

The control of the projectile energy is very important from the fatigue testing point of view. In this chapter calculation and measurement results of muzzle velocity and energy vs. capacitance and initial voltage have been presented (Figs. 12-15). It should be mentioned, that there is a very high repeatability of shots for this kind of railgun $[19,20]$.

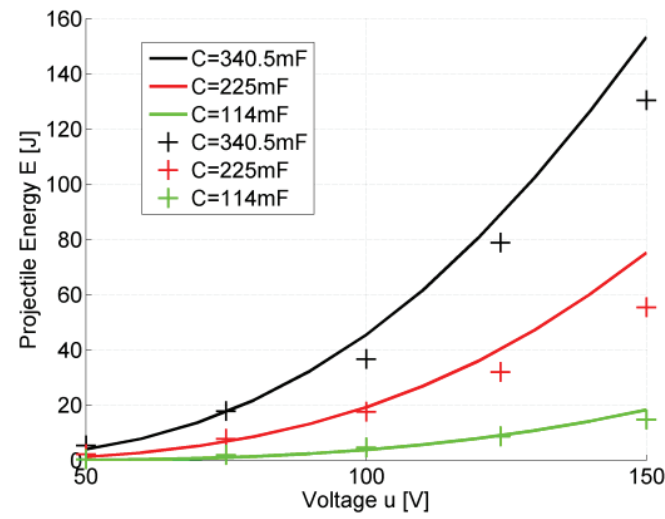

Fig. 12. Projectile energy vs. capacitance and initial voltage values (measurements are denoted by + )

The projectile energy increases, as expected, exponentially to the capacitor voltage (Fig. 12). The 
muzzle velocity changes almost linear vs. capacitor voltage (Fig. 13). The calculation model works better for lower energies. The differences between calculations and measurements are increasing vs. capacitance value. It means, that the mathematical model needs some improvements, especially in the area of mechanical phenomenon.

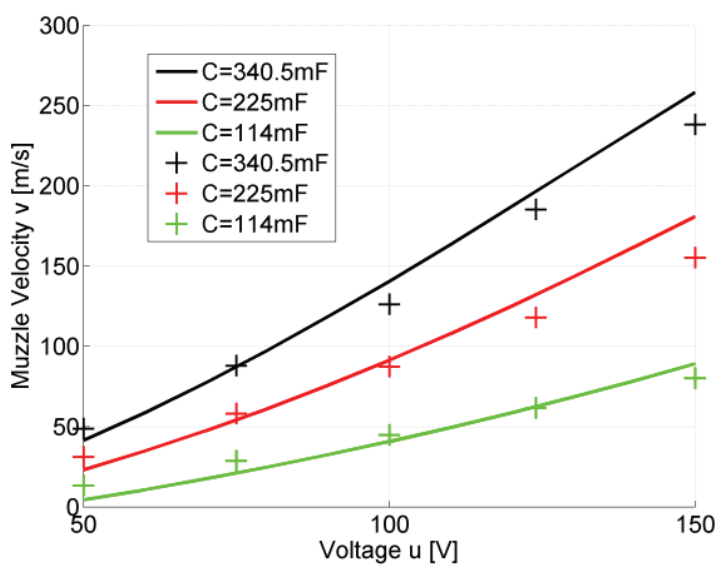

Fig. 13. Muzzle velocity vs. capacitance and initial voltage values (measurements are denoted by + ).

The mathematical model allows to estimate the projectile energy for higher voltages, than presented in Figs. 12 and 13. Thus, there has been carried out analysis for initial voltages, which are presently not possible to set in the measurement stand. In Figs. 14 and 15 some results have been given.

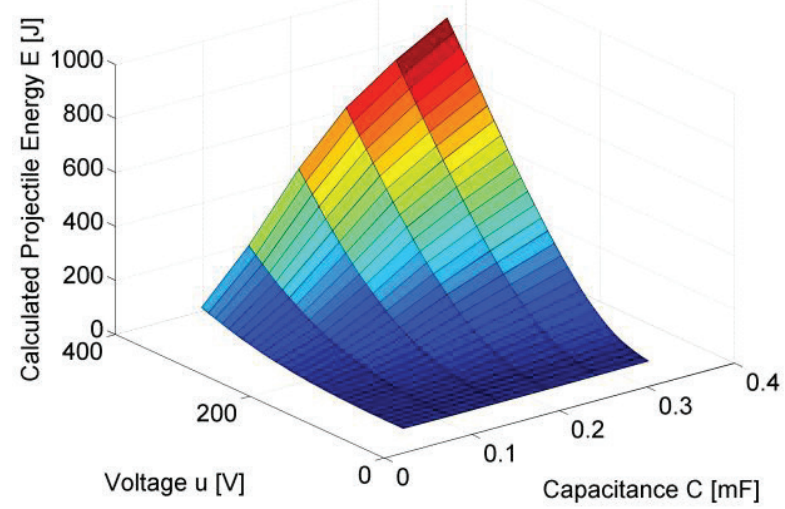

Fig. 14. Calculated projectile energy vs. capacitance and initial voltage values.

For very high energies, not analysed in the experiments, the friction and drag force are playing an important part. Thus, for voltage values higher than $170 \mathrm{~V}$ and capacitances higher than $250 \mathrm{mF}$, the projectile energy increases almost linearly vs. capacitor voltage (Fig. 14). It means, that the muzzle velocity increases slowly than the voltage (Fig. 15).

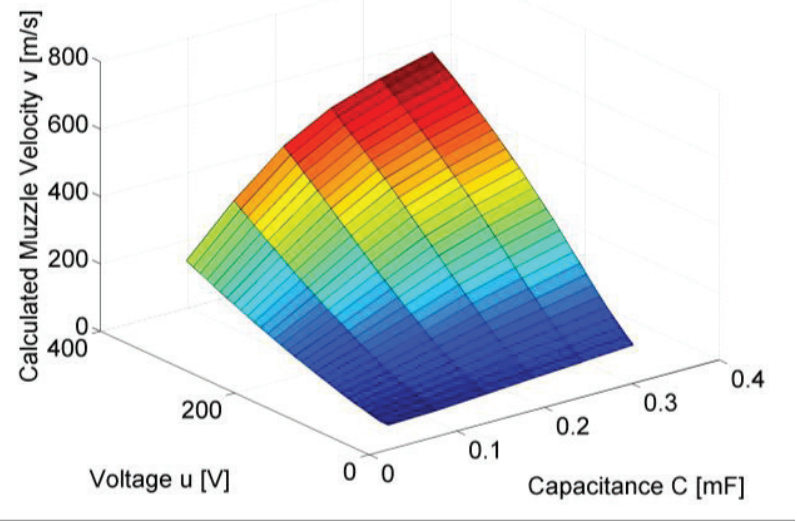

Fig. 15. Calculated muzzle velocity vs. capacitance and initial voltage values.

\section{Conclusions}

Concluding, presented characteristics of the muzzle velocity and energy of the projectile vs. power supply parameters indicate, that there is a capability to use accelerators for fatigue testing of materials. However, in order to predict the energy of the projectile, the proper mathematical model has to be formulated. The presented model is quite precise and could be used in prediction of projectile energy. Although, in relatively high energy range, the model should be improved, what will be done in future investigations.

Generally, for relatively low velocities (below 200$300 \mathrm{~m} / \mathrm{s}$ ) the projectile energy increases exponentially vs. voltage and nearly linear vs. capacitance value. For higher velocities, the drag force becomes an important factor. In this case, the energy increases linearly vs. supply voltage.

From Figs. 14 and 15 it is visible, that with using the presented laboratory stand, it is possible to reach energies of almost $800 \mathrm{~J}$. Further optimization of the electrodynamic accelerator construction and supply system should make possible improving of this value.

The increasing demand for fatigue testing of materials in high energy range (e.g. impacts in the space), satisfies the importance of presented investigations.

\section{References}

1. S. Katsuki, H. Akiyama, N. Eguchi, M. Sued, M. Soejima, T. Maeda, K.M. Sato, IEEE Trans. Magn. 31, 183-188 (1984)

2. D.A. Sink, L.J. Krzastek, IEEE Trans. Magn. 27, 266-271 (1991)

3. M. Tower, C. Haight, IEEE Trans. Magn 20, 298-301 (1984)

4. S. Hundertmark, M. Schneider, D. Simicic, G. Vincent, IEEE Trans. Plasma Sci. 42, 3180-3185 (2014)

5. J. McFarland, I.R.A. McNab, IEEE Trans. Magn. 39, 289-294 (2003)

6. M. Schneider, G. Vincent, J.D. Hogan, J.G. Spray, IEEE Trans. Plasma Sci. 43, 1162-1166 (2015) 
7. J.D. Hogan, J.G. Spray, R.J. Rogers, G. Vincent, M. Schneider, Int. J. Impact Eng. 62, 219-228 (2013)

8. S.A. Poniaev, S.V. Bobashev, B.G. Zhukov, R. O. Kurakin, A.I. Sedov, S.N. Izotov, S.L. Kulakov, M.N. Smirnova, Acta Astronaut. 109, 162-165 (2015)

9. P. Lehmann, B. Reck, M.D. Vo, J. Behrens, IEEE Trans. Magn. 43, 480-485 (2007)

10. L. Tang, J. He, L. Chen, S. Xia, D. Feng, IEEE Trans. Plasma Sci. 43, 1585-1591 (2015)

11. L. Jin, B. Lei, Q. Zhang, R. Zhu, IEEE Trans. Plasma Sci. 43, 1220-1224 (2015)

12. W. Xu, W. Yuan, Y. Sun, P. Yan, J. Li, IEEE Trans. Plasma Sci. 41, 1542-1546 (2013)

13. L. Chen, J. He, Z. Xiao, Y. Pan, IEEE Trans. Plasma Sci. 39, 417-421 (2011)

14. T. Boczar, A. Cichon, D. Wotzka, M. Kunicki, M Koziol, IEEE Trans. Dielectr. Electr. Insul. 24, 120128 (2017)

15. R. Beniak, O. Gudzenko, MMAR, 1104-1109 (2016)

16. J. F. Gieras, Z. J. Piech, B. Z. Tomczuk, Linear synchronous motors, (CRC Press, Taylor \& Francis Group, 2011)

17. J. Domin, K. Kluszczyński, Prz. Elektrotech. 89, 2125 (2013)

18. A. Waindok, P. Piekielny, SELM, 51-52 (2013)

19. A. Waindok, P. Piekielny, Prz. Elektrotech. 92, 246249 (2016)

20. A. Waindok, P. Piekielny, Prz. Elektrotech. 93, 152155 (2017) 